\title{
Introduction to Research on Late Imperial China: a Perspective from the $U K$
}

Aiming to highlight thriving research on Ming and Qing China carried out by scholars trained and/or working in the United Kingdom, this special issue of $M Q Y J$ includes contributions by Professor Olivia Milburn (Seoul National University), Dr Ewan Macdonald (University of Cambridge), and Dr Gregory Adam Scott (University of Manchester), together with a review by Dr Chen Jiani (previously at soAs University of London, now at Zhongshan University, Zhuhai) of Yang Haihong's volume on Women's Poetry and Poetics in Late Imperial China: A Dialogic Engagement (Rowman \& Littlefield, 2017).

Olivia Milburn is Associate Professor at the Department of Chinese Language and Literature, Seoul National University. She received her $\mathrm{PhD}$ in the history of ancient China and Chinese literature at soAs University of London (2003), after completing her BA and MPhil in Chinese language and literature at Cambridge and Oxford. She has published extensively, authoring volumes and articles on a variety of topics related to ancient China (amongst them: "The Blind Instructing the Sighted: Representations of Music Master Kuang in Early Chinese Texts", Monumenta Serica, 2018; Cherishing Antiquity: The Cultural Construction of an Ancient Chinese Kingdom, Harvard-Yenching Institute Monograph Series, 2013; "Marked out for Greatness? Perceptions of Deformity and Physical Disability in Ancient China", Monumenta Serica, 2007; "Kingship and Inheritance in the State of Wu: Fraternal Succession in Spring and Autumn Period China", T'oung Pao, 2004). She is also the author of important annotated translations, such as The Spring and Autumn Annals of Master Yan (Brill, 2016), Urbanization in Early and Medieval China: Gazetteers for the City of Suzhou (University of Washington Press, 2015), and The Glory of Yue: An Annotated Translation of the Yuejue shu (Brill, 2010).

In her contribution to this issue of $M Q Y J$, entitled "Zhao Luanluan and Her Tale”, Milburn examines the fictional character of Zhao Luanluan 趙鸞鸞, the Yuan dynasty gentlewoman in the early Ming tragic story Luanluan zhuan 鸞鸞傳 (The Tale of Luanluan) by Li Changqi 李昌祺 (1376-1452). Milburn exposes the late Ming practice of misrepresentation of the poems attributed to Zhao within the story, casting light on their actual author, presumably Li himself. She also cautions readers about the consequences of misattribution, an 
ongoing trend whereby fictional female poets of the Ming dynasty are treated as genuine historical individuals.

Ewan Macdonald received his PhD at soAs University of London(2016) with a thesis on "Reimagining the Vernacular Story: Textual Roles, Didacticism, and Entertainment in Erpai", written under the supervision of Professor Tian Yuan Tan, and is now a research fellow at University of Cambridge. Focusing on the late Ming vernacular short story collections Paian jingqi 拍案 驚奇 (Slapping the Table in Amazement) and Erke pai'an jingqi 二刻拍案驚奇 (Slapping the Table in Amazement Volume Two), authored by Ling Mengchu 凌濛初 (15801644), Macdonald's thesis casts light on Ling's interpretation of the notion of (huaben) fiction, also in relation to Feng Menglong's 馮夢龍Sanyan 三 言 (Three Words) collections, as well as on his choice to prioritize the entertaining and didactic effects of the stories on their audience over literary respectability.

The collections of Paian jingqi and Erke paian jingqi are also the object of Macdonald's most recent and highly interesting article focused on the unbalanced influence exerted by the relatively progressive rhetoric on notions of gender in the works by heterodox thinker Li Zhi (1527-1602) on the rather conventional representations of women within the narrative texts.

"Women in Erpai: the gap between rhetoric and representation". NAN NÜ 20.2 (2018): 225-255

In his contribution, entitled "Loss, Nostalgia, and Hope: The Ming-Qing Transition in the Fiction of "The Hazy Crossing Ferryman of Xiaoxiang", Macdonald focuses on the literary representation of the Ming-Qing dynastic transition's trauma (or partial lack thereof) within the novellas written by an author known to us as Xiaoxiang mijin duzhe, "The Hazy Crossing Ferryman of Xiaoxiang".

Gregory Adam Scott is Lecturer in Chinese Culture and History at the University of Manchester. After receiving his $\mathrm{PhD}$ in Chinese Buddhism at Columbia University (2013), with a thesis entitled "Conversion by the Book: Buddhist Print Culture in Early Republican China", he was a postdoctoral fellow at the Institute for Advanced Studies in the Humanities at the University of Edinburgh and Leverhulme Early Career Fellow in the Asian Studies department at the University of Edinburgh. Scott has published numerous scientific articles on nineteenth and twentieth-century Chinese Buddhism, focusing in particular on the Buddhist revival in the work of Holmes Welch (2017), on the 1913 Pinjia Canon (2017), on Buddhist scriptural presses and distributors (2016), and on Chinese Buddhist periodicals in the Early Republic (2016). His important 
monograph on Building the Buddhist Revival: Reconstructing Monasteries in Modern China (Oxford University Press) is expected to come out early next year.

In his contribution to this issue, entitled "Reconstructing Buddhist Monasteries in Post-Taiping China", Scott analyses the impact that the devastating Taiping War exerted on Chinese religious sites and institutions, in particular in the Jiangnan region. Religious reconstruction occurring after the war-as noted by Scott—was initiated and financed mostly by local people, rather than by local gentry or officials, and did not necessarily concern the whole of the monasteries which had been partially or completely destroyed. While providing crucial concrete evidence with respect to the process of religious reconstruction, Scott also deals with the notion of the revival of Chinese Buddhism in the decades following the Taiping War, pointing out that one should not be misled to conceive of this "revival" as a return to the status quo, but rather as a "reimagination" of the morphology and function of the religious institution.

While working on different aspects of Chinese cultural practices during the Ming and Qing dynasties (and beyond), Olivia Milburn, Ewan Macdonald, and Gregory Adam Scott are representative of a highly committed community of scholars bearing strong linkages with British academia. Their painstaking research (each in their own field) adds significant pebbles to the complex mosaic of late imperial China's cultural history, bringing to light new material, literary or religious, and offering new critical readings, which place emphasis, as in these three contributions, on the notion of (mis)representation and reimagination with respect to both individual and collective practices.

\author{
Chiara Ghidini, Guest Editor \\ University of Naples L'Orientale \\ cghidini@unior.it
}

